Artículo

\title{
A propósito del monopolio gremial: Toledo, 1700-1837
}

\section{José Antolín Nieto Sánchez* ID \\ Universidad Autónoma de Madrid}

\section{INFORMACIÓN DEL ARTÍCULO}

\section{Historia del artículo:}

Recibido: 21 de septiembre de 2020

Aceptado: 5 de febrero de 2021

On-line: 24 de marzo de 2021

\section{Códigos JEL:}

N33

N6

N90

N93

Palabras clave:

Gremios

Trabajo

Siglo xviii

Toledo

\section{R E S U M E N}

A partir de una muestra de 3044 cartas de examen expedidas por los gremios de Toledo entre 1700 y 1837, este artículo pretende comprobar si se cumplía el denominado monopolio corporativo en aspectos como la entrada al gremio o la procedencia de sus integrantes. El estudio se basa en una urbe de tamaño medio que ha despertado mucho interés por sus siglos de esplendor - XVI- y ocaso - xVII-, pero poco por el siglo xVIII, en general, y sus actividades manufactureras, en particular. En el contexto del debate europeo sobre los gremios es importante recalcar la aportación de estas ciudades medianas, pues permiten sopesar el gran número de problemas inherentes a las relaciones campo-ciudad, que incluyen el papel de la inmigración de futuros artesanos del medio rural al urbano o el de las ciudades cabecera en la expedición de los certificados de destreza para poder operar en los pueblos.

(c) 2021 Asociación Española de Historia Económica

\section{About the guild monopoly: Toledo, 1700-1837}

\section{JEL classification:}

N33

N6

N90

N93

Keywords:

Guilds

Work

18th century

Toledo

\section{A B S T R A C T}

Based on a sample of 3044 guild master diplomas issued by the Toledo guilds between 1700 and 1837, this article aims to verify whether the so-called "corporate monopoly» was fulfilled in aspects such as entry to the guild or the origin of its members. The study is based on a medium-sized city, which has aroused much interest due to its centuries of splendor -XVI- and decline -xVII-; but little for the eighteenth century, in general, and its manufacturing activities, in particular. In the context of the European debate on craft guilds, it is important to emphasize the contribution of these medium-sized cities, as they allow us to weigh the large number of problems inherent in country-town relations, which include the role of immigration of future artisans from rural to urban areas or that of the leading cities in the issuance of certificates of skill to be able to operate in the towns.

() 2021 Asociación Española de Historia Económica

\footnotetext{
* Autor para correspondencia. Correo electrónico: jose.nieto@uam.es (José Antolín Nieto Sánchez).
} 


\section{A propósito del monopolio gremial: Toledo, 1700-1837}

Las dos últimas décadas han supuesto un avance en el saber del comportamiento de los gremios en las grandes ciudades de Europa. Los estudios continentales han permitido conocer el número de corporaciones, la densidad gremial -la relación gremios/habitantes urbanos - o sus vinculaciones con el poder político. Estas investigaciones, conocidas como el retorno gremial, resaltan el papel de las corporaciones artesanas -y de una institución cercana como el aprendizaje- en las innovaciones técnicas, y evalúan su grado de apertura o cierre a futuros miembros en variables como edad, procedencia geográfica o adscripción del oficio a unas determinadas familias (Shephard, 1996; Epstein y Prak, 2008; Lucassen, De Moor y Van Zanden, 2008; Prak et al., 2019; Prak y Wallis, 2020).

Pero no hay unanimidad y los gremios siguen siendo vistos como instituciones que regularon estrictamente el acceso a sus filas, lo que limitó la industria y economía continental. La corriente historiográfica encabezada por Ogilvie (2019) sostiene que los gremios restringieron el número de sus miembros y su procedencia al entorno local y a las familias de los miembros ya asentados. Con esta estrategia pretendían ganar estabilidad y seguridad, logrando unos beneficios a sus integrantes que negaban al resto de artesanos a los que impedían acceder a sus filas. Además, sus miembros tenían como privilegio elaborar y vender legalmente unos productos concretos, lo que les diferenciaba de los no agremiados. Este monopolio gremial en la producción y el trabajo excluía a muchos artesanos, pues, según Ogilvie, «los gremios buscan restringir la entrada para limitar la competencia». Esta perspectiva parte del supuesto control de las corporaciones sobre el gobierno urbano, plataforma que serviría para aceptar las reglas de los mismos gremios. En suma, estas instituciones son la causa principal de las restricciones de acceso a los mercados y un obstáculo al progreso. Su abolición abriría el camino de la industrialización y el crecimiento posterior.

Como vemos, el debate europeo examina aspectos cruciales del funcionamiento de la economía de la Edad Moderna y su devenir futuro. Uno de estos puntos trascendentales tiene que ver con la extensión y efectividad de las barreras gremiales en ámbitos como la incorporación de nuevos miembros, la formación de mercados de trabajo o la exclusión por motivos de etnia y sexo. Es un debate que pone en su centro las contradicciones de la economía de la Edad Moderna, pues las barreras iban de la mano de unas corporaciones caracterizadas por su diversidad que demostraron una capacidad secular de gestión y adaptación, vitales en la transmisión del conocimiento técnico (Belfanti, 2004; Munck, 2007), muy propensas a organizar sus propios mercados de trabajo (Reith, 2008), y no incompatibles con la subcontratación del trabajo (Lis y Soly, 2008) o el despliegue de formas capitalistas de la organización productiva (García Sanz, 1996).

En este sentido, nuestro objetivo es calibrar si se cumplía el monopolio gremial en aspectos como la entrada al gremio o la procedencia de sus integrantes. $\mathrm{O}$, de otro modo, conocer el grado de apertura o cierre de los gremios a los forasteros para poder evaluar su pretendido comportamiento exclusivo. La hipótesis que planteamos dista de explicar la decadencia de ciudades como Toledo, nuestro objeto de estudio, mediante las barreras gremiales, y más por las diferencias retributivas de ciudades cercanas.
En este punto, el tamaño de las ciudades importa. Los estudios de Ogilvie se han basado en pequeñas villas alemanas y ya Torras (2019), Benaul (1992) y Torró (2004) nos alertaron de la importancia de las peninsulares con menos de 10000 habitantes. Dado que existe ya un corpus historiográfico gremial sobre grandes ciudades españolas (Nieto 2013; Nieto y Zofío, 2015, 2016; Solá y Yamamichi, 2015; Franch, Navarro y Rosado, 2016; Franch y Navarro, 2020), aquí estudiamos una urbe de tamaño medio como Toledo, que ha interesado mucho por sus siglos de esplendor -xvI- y ocaso -xvII- (Montemayor, 1996; Nombela, 2003), pero poco por su siglo xvIII y sus actividades manufactureras (Santos, 2010). El análisis de estas ciudades medias puede permitir conocer el comportamiento de los gremios en la decadencia de la periferia europea, así como sopesar el gran número de problemas inherentes a las relaciones campo-ciudad, que incluyen el papel de la inmigración de futuros artesanos del medio rural al urbano o el de las ciudades cabecera en la expedición de los certificados de destreza para operar en los pueblos. En última instancia, el estudio del siglo xvIII facilita una mejor comprensión de la capacidad gremial para transformarse en un contexto hostil a su existencia.

En lo que sigue, el artículo presenta la fuente utilizada -las cartas de examen de acceso a la maestría gremial - para pasar a contextualizar el caso toledano, enfatizando el aparente peso de sus corporaciones. Otro apartado analiza la evolución de las nuevas incorporaciones, comparando las de las nuevas maestrías toledanas con las de otras ciudades de similar tamaño. Después, el estudio de las edades de entrada permite resolver la problemática del cierre o apertura gremial, aspecto que se complementa con la aproximación metodológica a la reproducción familiar de los agremiados. La movilidad geográfica de los artesanos que llegaron a ser maestros se aborda desde una perspectiva comparativa con los mercados de trabajo artesanos que se forjaron en las principales ciudades peninsulares. Por último, el análisis de las ventajas comparativas que una ciudad como Madrid tuvo con respecto a Toledo permite conocer una clave explicativa más adecuada del declive toledano que la aportada por las barreras gremiales.

\section{Fuentes}

Este estudio tiene como eje las 3044 cartas de examen del siglo xVIII y comienzos del xix custodiadas en el Archivo Municipal de Toledo ${ }^{1}$. Es importante reseñar el carácter municipal de la documentación, pues a diferencia de Madrid o Segovia, donde los gremios contrataban a escribanos para confeccionar los certificados que avalaban la destreza de los nuevos maestros, en Toledo era el ayuntamiento el que se valía de un escribano propio para redactar estas licencias. Gracias a ello, las cartas localizadas en este archivo están perfectamente agrupadas por gremios, y cubren un total de 34. Esta documentación presenta casos muy homogéneos que permiten elaborar

\footnotetext{
${ }^{1}$ La muestra recoge todas las cartas de examen toledanas -excepto, lamentablemente, las del Arte Mayor de la seda, que intuimos tenía unos desaparecidos libros propios de incorporación- y es comparable, pese a su menor cantidad, con las 9331 cartas recogidas para Madrid en el mismo período, o con ciudades francesas como Rouen (8488) o Dijon (7880), por solo citar las que tienen estudios de todas las expedidas por los gremios (Nieto, 2013; Prak et al., 2019).
} 
series de los gremios más nutridos numéricamente. Los ocho gremios que sobrepasan el centenar de exámenes aglutinan 2071 cartas; los veintiséis restantes oscilan entre 1 -boticarios- y 69 cartas -confiteros-, y recogen un total de 973.

\section{Tabla 1}

Muestra de cartas de examen de Toledo, 1700-1837

\begin{tabular}{|l|c|c|l|r|r|}
\hline Gremios & Total & $\mathbf{\%}$ & \multicolumn{1}{c}{ Gremios } & Total & \% \\
\hline Zapateros & 367 & 12,2 & Plateros & 53 & 1,7 \\
\hline Sastres & 333 & 11 & Caldereros & 52 & 1,7 \\
\hline Albañiles & 312 & 10,6 & Esparteros & 45 & 1,4 \\
\hline Carpinteros & 301 & 10 & Pasteleros & 39 & 1,2 \\
\hline Pañeros & 276 & 9,1 & Tintoreros de paños & 38 & 1,2 \\
\hline Pasamaneros & 249 & 6,9 & Guarnicioneros & 38 & 1,2 \\
\hline Cerrajeros & 121 & 4 & Cedaceros & 36 & 1,1 \\
\hline Cereros & 112 & 3,7 & Cabestreros & 36 & 1,1 \\
\hline Tintoreros de seda & 95 & 3,1 & Guanteros & 33 & 1 \\
\hline Cuchilleros & 87 & 2,8 & Menos de 30 cartas & 299 & 10 \\
\hline Confiteros & 69 & 2,2 & & & \\
\hline Sombrereros & 53 & 1,7 & Total & $\mathbf{3 0 4 4}$ & $\mathbf{1 0 0}$
\end{tabular}

Fuente: AMT, Fondo Histórico. Cajas 6041-6064 y Libros manuscritos 143144 (para los pasamaneros), en adelante se cita como «Cartas de examen».

Las cartas proporcionan datos muy fiables sobre el volumen total de nuevos maestros, la cronología de la reproducción gremial, la edad de incorporación a la maestría o la procedencia geográfica. La información toledana es menos rica en la transmisión del oficio entre familiares. Para este artículo hemos elaborado una base de datos con los principales rubros que aparecen en las cartas, lo que permite indagar en el comportamiento corporativo, así como en la formación de los cualificados mercados de trabajo artesano y en el flujo migratorio que atraía la ciudad. Como veremos en algunas de las tablas, no siempre disponemos del total de información en todos los campos estudiados, pero la documentación manejada proporciona una inmejorable ocasión para conocer la movilidad de una fracción muy relevante del factor trabajo. Para conocer las barreras corporativas a la entrada de futuros maestros se han consultado varias recopilaciones de ordenanzas gremiales (Martín, 1858; Sáez, 1944-1947; Montemayor, 1996, p. 208).

\section{El aparente peso gremial en Toledo}

Durante el siglo xvIII Toledo tuvo muchos problemas demográficos. Si en 1694 tenía 20000 habitantes, estos permanecieron casi inalterados hacia 1750 -19488- para descender hasta 18021 en 1787. Así, la tasa anual acumulativa de todo el período fue negativa $(-0,11)$, siendo especialmente importante entre 1750 y 1787, cuando fue de $-0,21$. Además, Toledo estaba perdiendo peso con relación a su entorno: si en 1591 su población representaba el $14 \%$ del vecindario total de la provincia, en 1787 ese porcentaje había descendido a la mitad (González Agudo, 2015, pp. 34-35).

Esta atonía de la población urbana se refrenda en el total de la dedicada a la actividad artesana: su 46,7 \% de población ocupada en la industria en 1750 estaba muy lejos del 71,1\% de Segovia, o el 59,6\% de Palencia, los líderes manufactureros de Castilla (Nieto, 1999, p. 240). Por ello, si atendemos a la concepción que Llopis y Pérez Moreda (2003, p. 114) han dado a la ciudad -un núcleo es urbano si los activos agrarios no superan la mitad de su población ocupada-, Toledo no había perdido su carácter urbano, aunque este estaba muy tocado. La foto fija del Catastro de la Ensenada muestra un 24,4\% de población ocupada en el sector primario y un $28,9 \%$ en el de servicios (Nieto, 1999, p. 241). Dicho esto, lo más grave es que en la industria no se atisbaba un recambio por la vía de la aparición de nuevas ocupaciones.

Durante la Edad Moderna Toledo dependió de la industria de la seda. Como Valencia o Lyon, Toledo contaba con un importante número de talleres sederos, aunque en el siglo xviII el sector no pudo adaptarse a los cambios técnicos y de demanda que se sucedieron en el continente europeo (Navarro y Franch 2020; Pérez, 2008). Con todo, las cifras de mediados del siglo XVIII siguen manteniendo el predominio de la sedería con 208 maestros, 273 oficiales y 300 aprendices, mientras que el resto de grandes oficios eran los tiradores de seda (76 maestros), y los más tradicionales zapateros (123 operarios incluyendo maestros, oficiales y aprendices), sastres (121), pasamaneros (117), carpinteros (70) y albañiles (70). La estructura tripartita formada por maestros, oficiales y aprendices era muy desigual, con un predominio de los dos primeros grupos -740 maestros y 761 oficiales - y un número muy bajo de aprendices (543 o el $26,5 \%$ en relación a maestros y oficiales). Sin una base de reproducción del sector era muy difícil afrontar un cambio significativo de este, máxime cuando el grueso de los maestros sederos solo conservaba el título de tal, pues, como vamos a ver, eran meros dependientes de los comerciantes que controlaban la producción.

El grueso del artesanado toledano se organizaba en gremios. Sus números no cambiaron mucho entre 1600 y 1700, pues a los 43 de la primera fecha solo se añadieron 6 en la segunda. 49 gremios fue el número activo en 1800 . Esta estructura corporativa se había fraguado en el siglo xvi cuando se constituyó el grueso de los gremios toledanos. En suma, según el término acuñado por Mocarelli (2009), la "densidad gremial» en el siglo xVIII era de un gremio por 370 habitantes, es decir, un peso aparentemente abrumador de las corporaciones sobre la vida urbana. Y decimos en apariencia porque si el sector estrella de Toledo seguía siendo la sedería, esta se organizaba de una manera particular en la que los gremios no controlaban todos los aspectos de la producción.

El siglo xvIII no fue el período más esplendoroso de la sedería toledana, pero sirvió al capital mercantil representado en sus principales "mercaderes de escritorio» para afianzar su posición concentrando telares y operarios. A mediados del siglo, este afianzamiento tuvo lugar mediante la creación de «compañías de comercio y manufacturas» que aunaban colectivamente los intereses de todos los mercaderes del sector. En 1748 se organizó en Toledo una Compañía de Comercio y Manufacturas, que contó con los privilegios de la Junta de Comercio y Moneda -el organismo que dirigía la política industrial del momento-, gracias a los que comenzó a acaparar el suministro de seda cruda, el trabajo y los medios de producción. La concentración se evidencia en el Catastro de Ensenada. En Toledo, la Compañía tenía a su servicio casi a dos de cada tres maestros (128), más de la mitad de los aprendices y tiradores (225) y todos los oficiales de la ciudad (274), 
amén de 900 devanadoras. La pequeña producción artesana dependía de la Compañía; el sistema en el que el pequeño productor trabaja por encargo del comerciante -o verlagssystem- se apoderó de Toledo (García Ruipérez, 1986, pp. 94-99; Santos, 2010).

La pérdida de la independencia artesanal que comportaba el verlagssystem sedero tuvo consecuencias, dado el efímero resurgir de la sedería que trajeron las compañías de mercaderes. El fracaso de estas devolvió el protagonismo a los verlager individuales, pero la producción siguió una evolución negativa debido a que aquellos se desentendían de la inversión industrial a la mínima fluctuación del mercado y anteponían la obtención del beneficio a corto plazo que lograban con la venta de seda en rama o las importaciones de tejidos. Esta facilidad del capital para diversificar sus inversiones y disminuir los riesgos es causa de buena parte de la debilidad del verlagssystem sedero (Santos, 1998; Nieto, 1999).

La crítica situación del sector sedero arrastraba a la ciudad a una problemática incierta económica y laboralmente. Pese a esta dependencia estructural de la sedería, una parte importante de los principales gremios de Toledo tenía el respaldo del gobierno urbano. El ayuntamiento refrendó así nuevas ordenanzas corporativas en el siglo xviII y confió en los gremios el control de la calidad de la producción, como ocurrió en la pañería segoviana (García Sanz, 1996). Gracias al apoyo municipal los gremios de Toledo pudieron influir decisivamente sobre las poblaciones bajo la jurisdicción de la ciudad.

Es importante remarcar que desde el siglo xvi los gremios eran instituciones subordinadas al control del mismo ayuntamiento, y no al revés, como sostiene Ogilvie. Este control se aprecia en el ámbito de las cartas de examen, que no eran otorgadas por los gremios, sino por el consistorio toledano. Este se reservó pronto la posibilidad de designar un sobreveedor entre los miembros del cabildo para presenciar los exámenes y acudir a las inspecciones de los talleres. La pérdida de autonomía corporativa era el reflejo de la hegemonía en el ayuntamiento de los intereses de los fabricantes y mercaderes locales, muchos de ellos regidores y jurados del mismo consistorio (Aranda, 1992; Nombela, 2003, pp. 87-91).

\section{La evolución de las nuevas maestrías}

Desde el siglo xvi el examen fue el principal filtro de entrada utilizado por los gremios de Toledo para seleccionar a los artesanos que quisieran ser miembros de pleno derecho de ellos. Lo atestigua el interés gremial por fijarlo en sus ordenanzas. Este instrumento venía de la mano de la incorporación a la escala laboral de un grado intermedio entre la maestría y el aprendizaje como era la oficialía o lo que en Toledo se denominaba «laborante». De hecho, corporaciones como la de los albañiles no contemplaban todavía en sus ordenanzas de 1534 el grado de oficial, de manera que para obtener la maestría los aprendices necesitaban cuatro o cinco años de adiestramiento -dependiendo de si el aspirante se especializaba en «obra llana» o "prima»- y realizar correctamente el examen. Otras ordenanzas solo especificaban el período obligatorio de servicio previo a la maestría: las de cordoneros de 1543 obligaban a «haber servido» el oficio durante cinco años con maestro conocido; las de sombrereros (1585) cuatro años de aprendiz, y tres las de cedaceros (1588).

Las ordenanzas del xvi fijaban ya la gradación clásica de aprendiz y oficial: las de 1616 del arte de la seda obligaban a haber ejercido un año de «laborante», mientras que las de los violeros de 1617 exigían cuatro años de aprendiz y dos de oficial. Esta debía ser ya la norma en el siglo xviII, pues las dos únicas ordenanzas de esta centuria así lo explicitan.

En el punto del examen la historiografía europea está dividida entre los que argumentan que los altos derechos exigidos a los aspirantes explicarían el cierre gremial y los que afirman que no eran una barrera infranqueable (Ogilvie, 2019, pp. 121123; Prak, 2008, p. 154). ¿Qué enseña Toledo? Por desgracia, las recopilaciones de ordenanzas donde aparecen las obligaciones a pagar por los aspirantes a maestros apenas recogen ejemplos del siglo xviII, por lo que todo indica que seguían vigentes las cláusulas que sobre el examen se establecieron en el siglo xvi, verdadero momento fundacional de los gremios toledanos.

Las cifras de la tabla incluyen una horquilla de derechos que oscilan en el siglo xvi desde los 2 reales de los tejedores a los 34 de los sombrereros. El promedio de 15 reales no parece una traba infranqueable para obtener la maestría, aunque tampoco podrían serlo los valores algo mayores - hasta los 24 realesque pagaban bordadores, boneteros, calceteros y ciertos carpinteros. Solo podrían haberlo sido los 67,5 reales exigidos a los candidatos al arte de la seda en el siglo xvir, y que triplicaban lo exigido en el siglo anterior. Más adelante, el Catastro de la Ensenada permite conocer qué le suponía a un oficial el importe de estos derechos. Si un oficial espartero ganaba 4,5 reales en 1750 , las tasas de 30 reales suponían algo menos de seis días de trabajo, cantidad que no disuadía a los aspirantes a integrarse en la maestría.

El desincentivo al acceso a la maestría en Toledo pudo proceder de las tasas más bajas de examen exigidas en ciudades cercanas (Madrid) o competidoras (Valencia). Las que conocemos de Madrid no ratifican este supuesto: los 22 reales que exigían los carpinteros madrileños desde 1668 eran muy similares a los 24 y 30 de sus colegas toledanos, lo mismo que los cabestreros (11 en Madrid, 17,5 en Toledo) (Nieto, 2006, p. 207). Y menos competencia representaban los 1219 reales que el Arte Mayor de la seda aplicaba a los forasteros en Valencia en el siglo xviII (Franch, Muñoz y Rosado, 2016, p. 20).

¿Cómo evolucionó durante el siglo xviI la incorporación de nuevos miembros en los gremios? Toledo sufrió como pocas ciudades el impacto de la guerra de sucesión y entre $1704 \mathrm{y}$ 1716 solo se concedieron un promedio de 14 maestrías/año. La recuperación fue muy abrupta en la década de 1720 , con incorporaciones que llegan a su punto culminante en 1722 con 53 nuevas maestrías. Después hubo muchos altibajos, pero las incorporaciones tuvieron un nuevo pico a mediados de los años treinta. Desde entonces el ritmo se estabilizó con un promedio cercano a las 20-30 nuevas maestrías anuales. La década de 1780 conoció un repunte de nuevos maestros, pero las 11 incorporaciones de 1789 supusieron el mínimo histórico. El efecto rebote tardó en llegar, pero los años 1790 observaron un crecimiento que solo truncó la crisis de comienzos del siglo XIX. Entre 1803 y 1805 los gremios solo integraron a una media de 14 nuevos maestros. Superada esta crítica situación, en 1805 se alcanzaron cifras muy altas de incorporaciones (50 en 1807). La buena salud corporativa se volvió a quebrar con la guerra de la Independencia -aunque durante el conflicto siguieron los exámenes-, para descender su número durante el trienio liberal. Un posterior efecto rebote no se consolidó, marcando una evolución descendente hasta la desaparición final de los gremios. 
Tabla 2

Derechos de examen exigidos a los aspirantes a maestros en Toledo, siglos XVI-XVIII (en reales)

\begin{tabular}{|c|c|c|c|c|}
\hline Gremios & $\begin{array}{c}\text { Fecha promulgación } \\
\text { ordenanzas }\end{array}$ & $\begin{array}{l}\text { Derechos } \\
\text { de examen }\end{array}$ & $\begin{array}{l}\text { Derechos } \\
\text { a foráneos }\end{array}$ & $\begin{array}{c}\text { Derechos a hijos } \\
\text { y yernos }\end{array}$ \\
\hline Bordadores & 1496 & 22 & & \\
\hline Colcheros & 1519 & 5 & & \\
\hline Tejedores de cortinaje y pasamanería & 1525 & No consta & 5 a valencianos & \\
\hline Boneteros & 1533 & 22 & & \\
\hline Arte mayor de la seda & 1533 & 22 & & 6 \\
\hline Yeseros y albañiles & 1534 & 16 & & \\
\hline Cordoneros & 1543 & 3,5 & & 3,5 \\
\hline Tejedores de seda & 1545 & 2 & & \\
\hline Tintoreros de seda & 1550 & 11 & 22 & 11 \\
\hline Carpinteros & 1551 & $\begin{array}{l}\text { Obra de tienda: } 24 \\
\text { Obra de fuera: } 30\end{array}$ & & 6 \\
\hline Calceteros & 1552 & 12 & & \\
\hline Cabestreros & 1561 & 17,5 & & \\
\hline Espaderos & 1561 & 17 & & \\
\hline Sastres y jubeteros & 1561 & $\begin{array}{c}10 \text { los sastres } \\
5 \text { los jubeteros }\end{array}$ & & \\
\hline Guarnicioneros & 1566 & 6 & & \\
\hline Torcedores de seda & 1573 & 27 & & Exentos \\
\hline Sombrereros & 1585 & 34 & & 17 \\
\hline Calceteros & 1588 & 20 & & \\
\hline Arte mayor de la seda & 1616 & 67,5, más convite & & 32,5 \\
\hline Esparteros & 1751 & 30 & & \\
\hline Silleteros & 1766 & 30 & & \\
\hline
\end{tabular}

Nota: algunas cantidades podrían variar dependiendo del número de veedores y examinadores presentes en la prueba.

Fuente: elaboración propia a partir de Martín (1858) y Sáez (1944-1947).

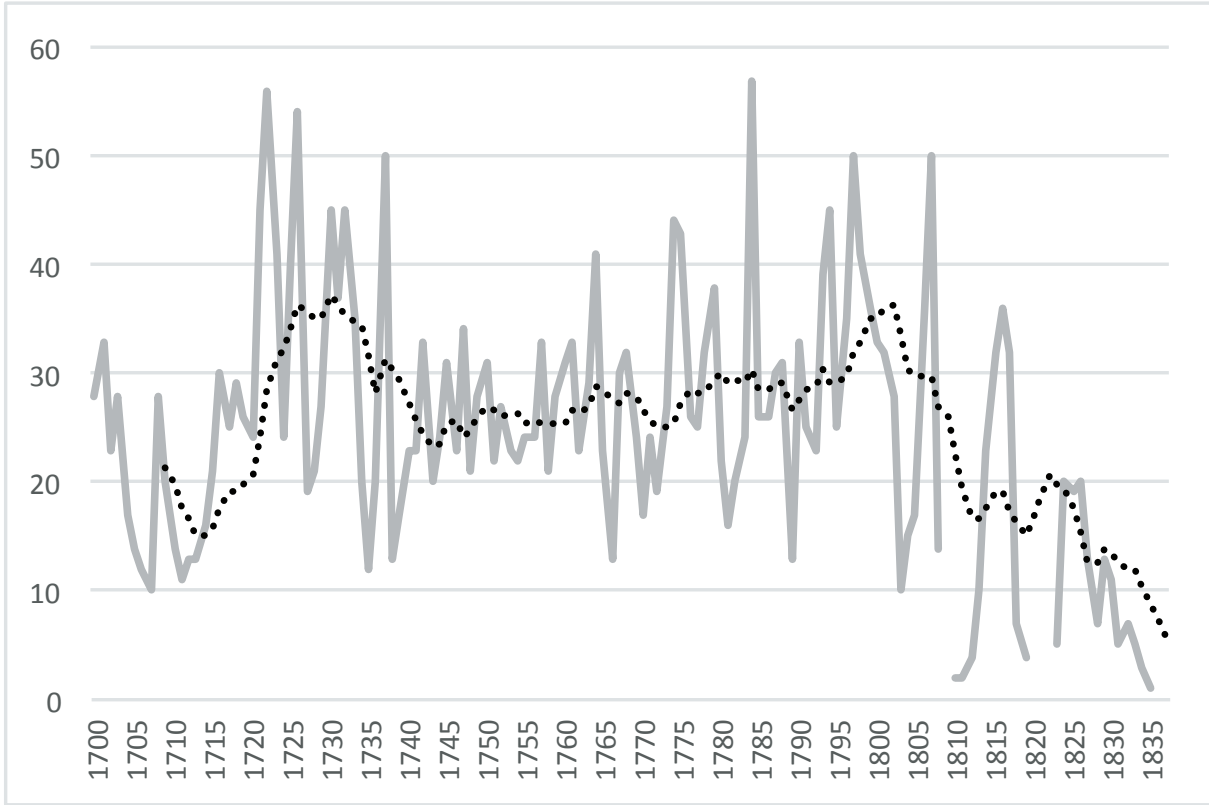

Figura 1. Evolución del número de nuevas maestrías y media móvil de diez años, Toledo 1700-1837.

Fuente: AMT, Fondo Histórico. Cajas 60416064 y Libros manuscritos 143-144. 


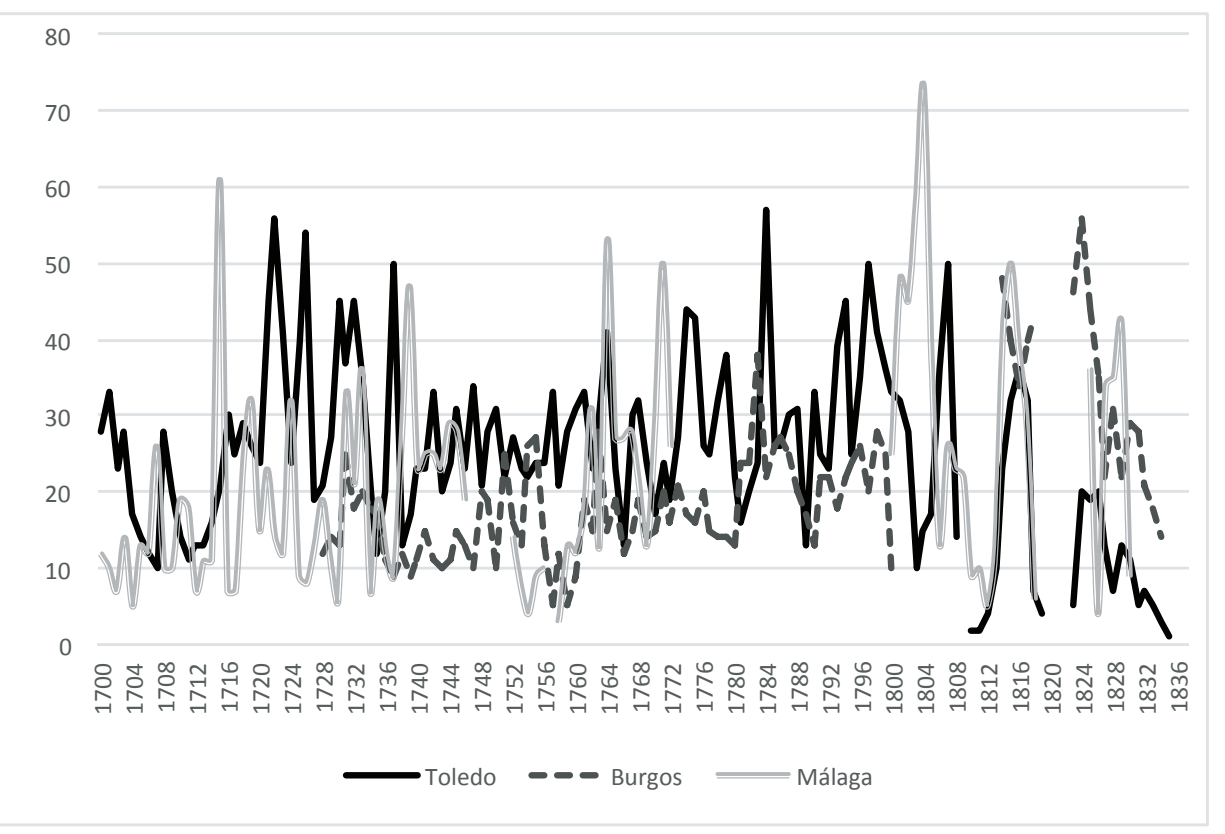

Figura 2. Cartas de examen de Toledo, Burgos y Málaga, 1700-1837.

Fuente: Cartas de examen de Toledo; Villas, 1982, Archivo Municipal de Málaga; Sanz 2019.

En suma, dejando al margen las convulsiones del período de la guerra de la Independencia y los años siguientes, las incorporaciones a los gremios toledanos raramente superaron los 50 nuevos maestros -el máximo histórico se produjo en 1784 con 54-, mientras que, en su base, los peores resultados llegaron con la contracción de la guerra de Sucesión -1707 con 10 nuevas maestrías - y los tremendos descensos de 1789 y, sobre todo, 1803 con 9 nuevas entradas. Pero el crecimiento de incorporaciones previo a la guerra de la Independencia sugiere que, como en Madrid, fueron decisiones políticas y no la ineficacia gremial lo que estaba tras los decretos de disolución de 1812.

¿La evolución de los gremios de Toledo era muy diferente a la de otras ciudades? Los gremios toledanos tuvieron una evolución propia de una ciudad que estaba intentando readaptarse a una nueva etapa económica. Si la comparamos con la evolución de otras ciudades medias, del interior y la periferia -Burgos y Málaga-, Toledo mantuvo una singladura relativamente similar a la primera ciudad, y sus números de incorporaciones -salvo picos puntuales- no desmerecían a los de Málaga, ciudad con 10000 habitantes más que Toledo y que se benefició del reequilibrio económico del que disfrutaba la periferia peninsular (Villas 1982; Archivo Municipal de Málaga; Sanz 2019).

\section{Gremios abiertos o cerrados según las edades de entrada}

La edad de entrada al gremio como maestro es una de las claves que permiten deducir las estrategias de reproducción pergeñadas por las corporaciones. Si un gremio quería cerrar la incorporación de nuevos miembros, podía subir las tasas de examen, lo que obligaba al aspirante a emplear más tiempo para ahorrar el dinero que permitiese afrontar ese gasto. Esta medida retrasaba la edad de incorporación al gremio como maestro. Gremios con dificultades económicas podían optar por bajar esas tasas facilitando que oficiales con menos recursos aspirasen a abrir un taller propio, previo paso por el tribunal examinador y el pago de los derechos de examen. En suma, conocer la estrategia de cada corporación puede acercarnos a saber si el monopolio gremial se cumplió o no en Toledo.

La homogeneidad de las series de los principales oficios permite analizar la secuencia secular de las edades de entrada ${ }^{2}$. La tabla 3 revela que en Toledo la tendencia general era entrar a la maestría poco antes de cumplir los 30 años. De esta tendencia solo escapan por arriba los albañiles - con 33 años de media de entrada - y por abajo los cereros y confiteros, que entraban hacia los 25 años. Es decir, entre los oficios de entrada precoz y el más propenso a incorporar a mayores de 30 años, distan 9 años de diferencia en la edad de entrada, lo que puede explicarse por el alto número de oficiales que no eran de Toledo, la importante competencia del trabajo no cualificado, la tendencia a la profesionalización del oficio, una necesaria larga práctica previa y una marcada dependencia de la estacionalidad de la demanda; por su parte, cereros y confiteros eran oficios muy ligados entre sí, con un porcentaje alto de maestros de fuera de Toledo, un corto aprendizaje previo en sus lugares de origen y una demanda constante.

Esta tendencia general se combina con otras que afectan a coyunturas concretas. La primera está representada por una evolución muy estable temporalmente, como ocurre con los carpinteros, gremio que mantuvo la edad de sus incorporados entre 29 y 32 años. Sastres y zapateros también se distinguen por desviaciones típicas muy pequeñas, con una horquilla general similar a la de los carpinteros. Por su parte, los nuevos maestros albañiles presentan una horquilla más avanzada, de

\footnotetext{
2 Las cifras aportadas son el fruto de contar las edades de los nuevos maestros que tenían 16 o más años en el momento de obtener la carta. Se han eliminado 46 casos con edades entre los 4 y 15 años, pues obedecían a las prácticas de privilegiar a los parientes de los veedores sin tener obligación de ejercer finalmente el oficio. Esta práctica se explicita en algunos casos ("por el privilegio concedido a los hijos de los veedores"), lo que justifica elegir esta edad para eliminar a estos nuevos maestros de la muestra, así como obrar de igual modo cuando la edad tan temprana es sospecha de tener un padre o veedor agremiado. El número de casos evidencia que fue práctica minoritaria, tardía y concentrada en gremios concretos (desde la década de 1760, entre los cerrajeros, y desde la de 1770 entre confiteros, pañeros, sastres y carpinteros.
} 
31 a 33 años, que solo en el convulso comienzo del siglo XIX cambió bruscamente a la baja y tras la guerra de la Independencia alcanzó su máximo de 36,2 años. Otros gremios tuvieron evoluciones muy diferentes, destacando la desviación típica de los pañeros, que pasaron de incorporarse muy tarde -36 años en 1710-1719- a experimentar un cambio abrupto a mediados del siglo y concluir con 19,8 años, el promedio más bajo de todos los gremios. Este rejuvenecimiento se explica por las reconversiones experimentadas en muchos de los pueblos de la llamada "nebulosa toledana», espacio industrial cercano a Toledo del que procedía el grueso de los nuevos pañeros (Nieto, 2000).

Tabla 3

Promedio de edad de entrada, mediana y desviación típica de los principales gremios, Toledo 1700-1837 (por décadas)

\begin{tabular}{l|cccccccccc}
\hline & Albañiles & Carpinteros & Cereros & Cerrajeros & Confiteros & Pañeros & Pasamaneros & Sastres & Zapateros \\
\hline $1700-09$ & 32 & 31,3 & 23,3 & 28,8 & 23,8 & 31,7 & 32,5 & 29,7 & 27,6 \\
\hline $1710-19$ & 31,2 & 31,7 & 26,8 & 26,4 & 23,2 & 36,2 & 28,6 & 28,7 & 30,1 \\
\hline $1720-29$ & 30,8 & 31,8 & 22,8 & 30 & 24,7 & 35,8 & 27,2 & 32,7 & 31,4 \\
\hline $1730-39$ & 33,3 & 29,3 & 24,6 & 29,5 & 25,9 & 33,4 & 25,3 & 28,6 & 30,6 \\
\hline $1740-49$ & 33,3 & 32 & 22,2 & 28,3 & 27,2 & 39,3 & 26,3 & 29,6 & 28,4 \\
\hline $1750-59$ & 31,8 & 29,6 & 22 & 24,2 & 22,6 & 39,4 & 25,8 & 28,9 & 29,1 \\
\hline $1760-69$ & 35 & 29,5 & 24,7 & 27,6 & 25 & 25,8 & 24,5 & 27,8 & 27,8 \\
\hline $1770-79$ & 32,5 & 30,5 & 32,4 & 25,8 & 27,7 & 26,3 & 30,2 & 30,8 & 27,7 \\
\hline $1780-89$ & 33,6 & 28,9 & 27 & 30,4 & 24,1 & 34,1 & 28,7 & 28,4 & 32,8 \\
\hline $1790-99$ & 33,3 & 30,7 & 27,1 & 29,5 & 21,7 & 26,6 & 25,1 & 28,6 & 28,3 \\
\hline $1800-09$ & 29,8 & 30,7 & 22 & 33,2 & 24,5 & 22,9 & 29 & 26,8 & 27,3 \\
\hline 1810-19 & 36,2 & 32 & 24,6 & 35 & 23,7 & 20,1 & 33,3 & 27,4 & 27,2 \\
\hline 1820-29 & 34 & 30,9 & 24,6 & 32,3 & 24 & & 42,4 & 24,7 & 26 \\
\hline 1830-37 & & 29 & 19 & 33 & 23,9 & & & 32 & 23 \\
\hline Media total & 33 & 31,6 & 25,2 & 28 & 24,4 & 29,6 & 27,6 & 29,09 & 29,06 \\
\hline Mediana & 33,3 & 30,7 & 24,6 & 29,5 & 24 & 32,5 & 27,9 & 28,6 & 28,05 \\
\hline $\begin{array}{l}\text { Desviación } \\
\text { típica }\end{array}$ & 1,74 & 1,12 & 3,20 & 3,06 & 1,63 & 6,54 & 4,84 & 2,05 & 2,42 \\
\hline
\end{tabular}

Fuente: cartas de examen.

\section{El debate de la endotecnia}

Entre los defensores del monopolio corporativo se ha solido contemplar la reproducción gremial mediante los privilegios que las ordenanzas incluían a favor de los hijos de los maestros. Es la célebre endogamia, o la más correcta endotecnia (Díez, 1990, p. 29), es decir, el reclutamiento del trabajo cualificado mediante aportes familiares. ¿Qué dicen al respecto las reglas toledanas?

En las 34 ordenanzas disponibles -como vimos mayoritariamente del siglo xvI- solo la mitad adoptaron medidas relativas a los hijos de los maestros. Es decir, la más que probable falta de revisiones posteriores a las ordenanzas del xvi sugiere que se mantuvo un cierto trato de favor hacia los hijos de los maestros, pero no se pusieron medidas adicionales. Veamos algunos ejemplos.

Comencemos con una excepción a la regla de privilegio a los parientes de los agremiados. Las ordenanzas de colcheros de 1519 obligaban a sustituir a los parientes que formasen parte del tribunal examinador de un aspirante. Es una norma que revela que pronto hubo intentos de copar estos tribunales, así como que ciertos gremios activaron medidas para evitarlo. Las ordenanzas son mucho más prolijas al incluir capítulos permisivos con los hijos de los maestros. Hubo gremios, como guarnicioneros y cerrajeros, que examinaban con normas más estrictas a los ajenos a la familia gremial. Pero la mayoría rebajó (carpinteros, tintoreros de seda, sastres, sombrereros, sederos) o eximió completamente a sus hijos de los derechos de examen (torcedores). En 1766 los silleros de paja no eliminaron estos derechos a sus hijos, pero les exigían haber trabajado cinco años con sus padres u otros maestros. Esta exigencia se compensaba con la reducción del número de piezas que realizar en el examen. Con todo, hubo excepciones: en 1588 los cedaceros obligaban a los hijos de maestros a examinarse para poner tienda, bajo pena de 2000 maravedíes; y en 1617 los vihueleros les permitían examinarse solo de los instrumentos musicales que conocían, pero les impedían usar el resto. En suma, las ordenanzas fijaban un conjunto de reglas dispares en respaldo a los hijos de los maestros. No hubo un patrón unívoco del pretendido monopolio gremial.

¿Qué dicen al respecto las cartas de examen? Las recopiladas para el siglo xvIII y comienzos del xix no reflejan exactamen- 
te la transmisión de la profesión entre miembros de la misma familia, pero hay indicios relativamente fiables de los privilegios de los hijos de los maestros en variables como la edad o la coincidencia de apellidos entre veedores y aspirantes. La tabla 4 permite acercarnos al grado de endotecnia de los gremios toledanos, pues las cartas de examen incluyen casos que explicitan la relación de parentesco (A); que muestran coincidencias en apellidos de nuevos maestros y examinadores (B), y donde la baja edad del aspirante revela su pertenencia a la familia gremial (C). Lo que sigue son cifras mínimas, a la espera de más aporte documental y la mejora de la metodología utilizada al respecto.

\section{Tabla 4}

Grado hipotético de endotecnia en los gremios de Toledo, 1700-1837

\begin{tabular}{|c|c|c|c|c|c|c|}
\hline \multirow[b]{2}{*}{ Gremios } & \multicolumn{3}{|c|}{ Parentesco } & \multirow[b]{2}{*}{ Total } & \multirow[b]{2}{*}{ Nuevas maestrías (total) } & \multirow[b]{2}{*}{$\%$} \\
\hline & Seguro $(A)$ & $\begin{array}{l}\text { Probable con } \\
\text { veedor (B) }\end{array}$ & Edad (C) & & & \\
\hline Albañiles & 1 & 26 & & 27 & 312 & 8,6 \\
\hline Cabestreros & 2 & 5 & & 7 & 36 & 19,4 \\
\hline Carpinteros & 2 & 29 & 1 & 32 & 301 & 10,6 \\
\hline Cereros & 1 & 8 & & 9 & 112 & 8 \\
\hline Cerrajeros & 6 & 20 & 1 & 27 & 121 & 22,3 \\
\hline Confiteros & 9 & 20 & 3 & 32 & 69 & 46,3 \\
\hline Cuchilleros & 2 & 9 & 1 & 12 & 87 & 13,7 \\
\hline Esparteros & 1 & 9 & 1 & 11 & 45 & 24,4 \\
\hline Guarnicioneros & & 8 & & 8 & 38 & 21 \\
\hline Pañeros & 1 & 22 & 6 & 29 & 276 & 10,5 \\
\hline Pasamaneros & 2 & 29 & 3 & 34 & 249 & 13,6 \\
\hline Plateros & 18 & & & 18 & 53 & 33,9 \\
\hline Sastres & 2 & 14 & 1 & 17 & 333 & 5,1 \\
\hline Sombrereros & 3 & 7 & & 10 & 53 & 18,8 \\
\hline Tintoreros seda & 3 & 36 & 1 & 40 & 95 & 42,1 \\
\hline Zapateros & & 22 & 1 & 23 & 367 & 6,2 \\
\hline Otros & 8 & 26 & 3 & 37 & 500 & 7,4 \\
\hline Total & 61 & 290 & 22 & 373 & 3037 & 12,2 \\
\hline
\end{tabular}

* Las cifras de la edad no coinciden con las ofrecidas más arriba en el texto debido a que en ocasiones baja edad y parentesco del oficio coinciden. Entonces se han incorporado esos datos en la columna de parentesco probable.

Fuente: cartas de examen.

Estos indicadores se pueden compaginar con otros como la repetición de apellidos entre todos los nuevos maestros -no solo los veedores-, lo que consolida la idea de la preponderancia de ciertas sagas familiares en gremios como los tintoreros de seda: cinco apellidos aglutinan a un total de 61 nuevos maestros o el $64 \%$ del gremio. Estas cifras provisionales reflejan que la endotecnia no era un problema real para el grueso de los gremios. Los había con unos porcentajes muy altos -los confiteros o los citados tintoreros de seda, con unos hipotéticos $46,3 \%$ y $42,1 \%$, respectivamente; o los plateros, con una cifra segura del $33,9 \%$-. Pero, por lo general, las corporaciones no superaron el $20 \%$ con parientes - padres, abuelos, hermanos o tíos- en sus filas. La media del 12,2\% de endotecnia en Toledo es más baja que la horquilla del $21 \%$ al $30 \%$ manejada en las investigaciones de otras ciudades europeas, pero hay que conceder que no hubo una norma específica del comportamiento de los gremios de cada ciudad continental (Prak et al., 2019, p. 8).

\section{La movilidad geográfica}

¿Qué posibilidades había de acceder a los gremios para un recién llegado a la ciudad? Sabemos poco sobre las dificultades que tuvieron los extraños a la hora de convertirse en miembros de un gremio, de modo que calibrar el peso de esta variable puede facilitar conocer la importancia de las restricciones económicas creadas por los gremios, máxime cuando el conjunto de reglas formales establecidas por estos para controlar quién podría obtener la entrada en la corporación se ha solido utilizar para resaltar la importancia de los obstáculos que tuvieron que salvar las personas sin conexión previa a los oficios urbanos. Y, por derivación, también se ha tomado como un indicador de las recompensas - privilegios-obtenidas por los ya incorporados, es decir, el mentado monopolio gremial.

Claro que, si los gremios generaron un volumen importante de beneficios para sus miembros, esto también pudo ser un 
aliciente para que otros, pese a los obstáculos, intentasen acceder a aquellos. Es, por tanto, necesario saber cuántos forasteros eran miembros del gremio o encontrar un indicador de la presencia de barreras efectivas a la entrada. $\mathrm{Si}$, como sostienen Prak y sus seguidores, el acceso al monopolio estaba abierto a un gran número de foráneos, entonces el exclusivismo de este monopolio no habría tenido tanta fuerza y los resultados desastrosos que se suelen afirmar.

En este punto, los estudios sobre los gremios castellanos y aragoneses pueden avalar la atonía o no de las ciudades estudiadas. La tabla 5 revela provisionalmente que en las grandes y medias ciudades de Castilla -con más de 10000 habitantes en algún momento del xviII- la reproducción gremial recayó en los naturales de la misma ciudad, pero no fue escasa la aportación de los procedentes del entorno, entendiendo por tal los artesanos de las villas y aldeas de la misma provincia. Si sumamos todos los no naturales de la ciudad, incluidos los no peninsulares, el aporte no local supone un 53,1\%, muy lejos de apoyar el monopolio gremial. Y si eliminamos a las ciudades más abiertas -Cádiz, Madrid-, cuatro de cada diez nuevos maestros no procedían de las ciudades donde se expedía el título, aún lejos de la hegemonía local. Una comparación con los principales gremios de Valencia - el arte mayor de la seda - y Barcelona - velers o tejedores de seda-, arroja magnitudes similares, aunque estos casos evolucionaron al cierre gremial. En suma, unos números más similares al modelo de Prak que al de Ogilvie, y que avalan que, como en otras áreas europeas, los gremios estaban organizando mercados propios de trabajo cualificado (Reith, 2008).

\section{Tabla 5}

Procedencia de los nuevos maestros de diez ciudades, 1675-1836

\begin{tabular}{|c|c|c|c|c|c|c|c|c|c|}
\hline & & & \multirow{2}{*}{\multicolumn{2}{|c|}{ Entorno }} & \multirow{2}{*}{\multicolumn{2}{|c|}{ Resto }} & \multirow{2}{*}{\multicolumn{2}{|c|}{ Foráneos }} & \multirow[b]{3}{*}{ Total } \\
\hline & \multicolumn{2}{|c|}{ Misma ciudad } & & & & & & & \\
\hline & Total & $\%$ & Total & $\%$ & Total & $\%$ & Total & $\%$ & \\
\hline \multicolumn{10}{|l|}{ CASTILLA } \\
\hline Zamora, 1700-1833 & 676 & 49,4 & 678 & 49,6 & 5 & 0,3 & 7 & 0,5 & 1366 \\
\hline Burgos, 1783-1835 & 286 & 67,9 & 57 & 13,5 & 70 & 16,6 & 8 & 1,9 & 421 \\
\hline Segovia, 1748-1811 & 710 & 67,4 & 296 & 28,1 & 46 & 4,3 & 1 & 0,09 & 1053 \\
\hline Madrid, 1700-1835 & 2758 & 32,5 & 813 & 9,5 & 4423 & 52,2 & 475 & 5,6 & 8469 \\
\hline Toledo, 1700-1835 & 1164 & 42,7 & 1078 & 39,5 & 416 & 15,2 & 65 & 2,3 & 2723 \\
\hline Cartagena, 1718-1835 & 221 & 43,1 & 173 & 33,7 & 88 & 17,1 & 31 & 6 & 512 \\
\hline Cádiz, 1699-1826 & 158 & 15,2 & 151 & 14,6 & 489 & 47,2 & 236 & 22,8 & 1034 \\
\hline Sevilla, 1690-1835 & 3705 & 72,8 & & & 1375 & 27,2 & & & 5080 \\
\hline TOTAL & 9678 & 46,8 & & & 10980 & 53,1 & & & 20658 \\
\hline \multicolumn{10}{|l|}{ ARAGÓN } \\
\hline Barcelona*, 1782-1824 & 400 & 66,5 & 198 & 32,9 & 3 & 0,4 & 0 & 0 & 601 \\
\hline Valencia*, 1686-1836 & 2900 & 58,3 & 1819 & 36,6 & 239 & 4,8 & 9 & 0,1 & 4967 \\
\hline
\end{tabular}

*Solo un oficio

Fuentes: archivos históricos provinciales de Zamora, Segovia, Cádiz; archivos históricos municipales de Burgos, Toledo y Cartagena; Archivo Histórico de Protocolos de Madrid; Bernal, García-Baquero y Collantes (2008, pp. 295-296); Franch, Muñoz y Rosado (2016); Solá y Yamamichi (2015); Nieto y Velasco (2018).

¿Y en Toledo? Varias ordenanzas del siglo xvi exigían volver a examinarse a los forasteros que llegaban a Toledo con la carta de examen conseguida en otra ciudad. En estos gremios hubo grados: las más restrictivas fueron las reglas de los pasamaneros de 1525, que ajustaron cuentas con sus homólogos valencianos. Nadie que viniese de fuera con carta de examen debía presentarse a este, excepto los valencianos, dado que en la ciudad del Turia se exigía volver a examinarse a los toledanos que acudían allí. En esta línea las reglas de los torcedores obligaban a los forasteros a examinarse de nuevo o a tener carta de su lugar de origen. En 1551 los carpinteros diferenciaban entre los oficiales forasteros que llegasen con un título específico y los que lo hiciesen con otro general; estos últimos deberían volver a examinarse. Las ordenanzas de yeseros y albañiles de 1534 obligaban a los forasteros que acudían a Toledo con carta de examen a pasar un mes de prueba supervisados por los veedores. Sin embargo, los cedaceros no exigían en sus normas de 1588 el examen a los que ya hubiesen obte- nido la carta en otro lugar. Esta fue la senda seguida en el siglo xVIII por esparteros y silleros de paja. En suma, las ordenanzas toledanas no introdujeron demasiados obstáculos a los oficiales forasteros. Solo los tintoreros de seda incorporaron en 1550 diferencias entre los aspirantes toledanos y los no toledanos: exigían el doble -2 ducados - a los forasteros.

Las cartas de examen apoyan que no hubo demasiadas trabas a los extraños, que representaban el 57,3\% de los nuevos maestros. Y también permiten analizar por oficios la entrada de nuevos miembros. Para ello hemos diferenciado los gremios por el número de sus nuevos integrantes, es decir, gremios con más o menos de 100 cartas. Entre los más grandes la reproducción no se fio a la procedencia endógena: de Toledo procedía el $40 \%$ de los nuevos maestros de estos oficios, siendo más importante el flujo de nuevos maestros del entorno provincial (43,7\%). Obviamente estos promedios ocultan diferencias sustanciales: en cinco gremios eran más los procedentes de la provincia (albañiles, cereros, cerrajeros, confiteros y pañeros), mientras que en 
cuatro lo eran los naturales de la misma ciudad (carpinteros, sastres, zapateros y, sobre todo, pasamaneros, con 7 de cada 10 nuevos maestros). Dicho esto, hay gremios que tienen un porcentaje nada despreciable de incorporaciones de Castilla La Mancha y Madrid (el 30\% de los cereros) o de un espacio más amplio entre los confiteros (uno de cada cuatro). Los no peninsulares solo sobresalen entre los zapateros (con una procedencia foránea diversa) y, sobre todo, los albañiles (portugueses). Como otros nuevos maestros del oficio, obtenían el título en la ciudad, pero no trabajaban en ella.

\section{Tabla 6}

Procedencia de los nuevos maestros en gremios con más de 100 cartas de examen

\begin{tabular}{|c|c|c|c|c|c|c|c|c|c|c|c|c|c|c|c|}
\hline & \multirow[b]{2}{*}{$\mathbf{N}$} & \multicolumn{2}{|c|}{ Toledo } & \multicolumn{2}{|c|}{ Provincia } & \multicolumn{2}{|c|}{$\begin{array}{l}\text { Castilla- } \\
\text { La Mancha }\end{array}$} & \multicolumn{2}{|c|}{ Castilla-León } & \multicolumn{2}{|c|}{ Madrid } & \multicolumn{2}{|c|}{ Otros } & \multicolumn{2}{|c|}{ Extranjeros } \\
\hline & & $\mathbf{T}$ & $\%$ & $\mathbf{T}$ & $\%$ & $\mathbf{T}$ & $\%$ & $\mathbf{T}$ & $\%$ & $\mathbf{T}$ & $\%$ & $\mathbf{T}$ & $\%$ & $\mathbf{T}$ & $\%$ \\
\hline Carpinteros & 271 & 138 & 50,9 & 96 & 35,4 & 14 & 5,1 & 7 & 2,5 & 5 & 1,8 & 9 & 3,3 & 2 & 0,7 \\
\hline Cereros & 99 & 21 & 21,2 & 41 & 41,4 & 21 & 21,2 & 1 & 1 & 10 & 10,1 & 5 & 5 & & \\
\hline Pañeros & 249 & 70 & 28,1 & 162 & 65 & 5 & 2 & 4 & 1,6 & 6 & 2,4 & 1 & 0,4 & 1 & 0,4 \\
\hline Pasamaneros & 235 & 169 & 71,9 & 35 & 14,8 & 5 & 2,1 & 11 & 4,6 & 5 & 2,1 & 10 & 4,2 & & \\
\hline Sastres & 315 & 174 & 55,2 & 93 & 29,5 & 10 & 3,1 & 7 & 2,2 & 11 & 3,4 & 20 & 6,3 & & \\
\hline Zapateros & 313 & 140 & 44,7 & 119 & 38 & 24 & 7,6 & 4 & 1,2 & 5 & 1,6 & 14 & 4,4 & 7 & 2,2 \\
\hline
\end{tabular}

Fuente: cartas de examen.

La mayoría de los gremios con menos de 100 cartas invierte las tornas al contemplar un predominio de nuevos maestros naturales de la misma Toledo. La mitad de esas nuevas incorporaciones son aportadas por Toledo, que lidera en 11 de los 16 oficios con más de 10 cartas (sobre todo, entre tintoreros de seda, guanteros y cabestreros, gremios en los que más del $70 \%$ de sus nuevos maestros se reclutaron en la ciudad). El peso de la provincia solo se dejó sentir entre tundidores y tintoreros de paño, mientras que destacan las incorporaciones de extranjeros -franceses - entre caldereros y cuchilleros, así como de madrileños entre los pasteleros. En suma, gremios con marcados rasgos de movilidad, que pueden apreciarse en otras ciudades (Nieto, 2013).

¿Qué revelan estos datos? Si establecemos unos umbrales porcentuales que fijen como gremios cerrados aquellos que integrasen a más del $50 \%$ de sus miembros entre los nacidos en Toledo y gremios abiertos a los que acogían a menos del $30 \%$ de los nacidos en la misma ciudad, 11 gremios eran cerrados y 9 abiertos. Es decir, un margen muy estrecho a favor de los primeros; pero si contamos el total de agremiados con procedencia, los gremios cerrados acogían a 890 nuevos maestros, por 1087 los abiertos.

Lo expuesto sobre la procedencia se matiza al introducir la variable vecindad, que plantea la dependencia de los pueblos de la jurisdicción de la ciudad con relación a esta, e incluso la de su entorno provincial. Y en concreto el papel de los gremios de Toledo, que mediante sus ordenanzas exigían a los artesanos del entorno examinarse en la ciudad para ejercer allí donde el oficial estaba avecindado.

Las cifras son elocuentes: de las 2685 cartas que recogen la vecindad, el $69,8 \%$ son de vecinos de Toledo, mientras que el resto lo son de nuevos maestros de la jurisdicción de Toledo, la misma provincia o provincias cercanas. Estos tres de cada diez nuevos maestros procedentes de fuera de la ciudad remiten al control de los gremios de esta sobre el entorno, o lo que es igual, la necesidad de obtener la carta en Toledo, actuando la ciudad como una cámara de registro de la certificación de la destreza artesana de una amplia área geográfica-; así como la conversión de Toledo en una alternativa a ciudades cercanas como Madrid, donde en ciertos gremios las tasas de examen eran más altas.

De la provincia actual de Toledo procedía el grueso de los nuevos maestros no avecindados en la ciudad -659 de un total de 810-, sobre los que los gremios toledanos ejercían jurisdicción. Y entre ellos destacan los nuevos maestros del sector pañero avecindados en la nebulosa industrial toledana, que aglutina el núcleo de los pueblos formado por Ajofrín y Sonseca (36 y 25, respectivamente), así como Novés (15), Escalonilla, Madridejos, Menasalbas o Consuegra. Algunos de estos pueblos habían intentado regular su producción de paños y habían obtenido ordenanzas propias -como los tres primeros pueblos citados-, pero excepto Novés, no lograron incluir en ellas el control sobre el examen (Nieto, 2000, 2012). Esta pauta de dispersión era compartida por gremios de otros sectores productivos como los caldereros. Quince de sus nuevos maestros estaban avecindados en la provincia y eran miembros de la diáspora francesa que se examinaba en Toledo para ejercer en sus pueblos de residencia.

Interesante es también el flujo de aspirantes que acudían a Toledo desde Madrid. Desde aquí llegan 77 nuevos aspirantes, ya porque se buscaba el prestigio del trabajo realizado en Toledo -el tinte- o porque se intentaban burlar las altas tasas de examen de ciertos gremios madrileños -armeros-, una práctica que generaba buenos ingresos para los gremios toledanos. También de la provincia de Madrid acudían en 1794 a Toledo nueve pañeros y 3 tundidores avecindados en Valdemoro -que seguramente trabajaban en la Real Manufactura establecida a 
finales del siglo- y algunos de Pinto o Colmenar de Oreja. En la misma línea de burlar tasas de examen altas están los cuatro aspirantes a tintoreros de seda procedentes de Requena.

¿Cómo se estableció el control de los gremios de Toledo sobre el entorno? Tenemos certezas fiables en la etapa más dura del siglo xvII mediante las causas criminales abiertas en los Montes de Toledo por ejercer el oficio sin estar examinado. Entre 1609 y 1630 se entablaron por este motivo 38 causas en 12 de esos pueblos. Los oficios que incluían a más «ilegales» eran los sastres y albañiles (11 causas cada uno), seguidos de barberos-cirujanos (6) y herradores-albeitares (5). En la misma Toledo se intuyen pleitos posteriores, pero solo se conocen las causas incoadas en 1772 contra un maestro sastre y en 1798 contra tres oficiales cuchilleros $^{3}$. En los expedientes de concesión de cartas de examen del siglo xviII también aparecen inspecciones gremiales y denuncias de las autoridades locales, lo que revela que junto a las causas se formó un dispositivo de control sobre el trabajo en los pueblos cercanos a la Ciudad Imperial.

\section{Las diferencias retributivas}

Los datos aportados apuntan a que el problema de los gremios toledanos no estaba ni en las tasas de examen ni la procedencia local de sus nuevos maestros o su envejecimiento. No derivaban, en suma, del supuesto monopolio gremial; eran consecuencia de algo más sencillo: en Toledo los oficiales y aprendices ganaban menos que en Madrid. En una comparación entre las retribuciones aparecidas en el Catastro de la Ensenada solo ganaban más en Toledo los oficiales albañiles,

\section{Tabla 7}

Diferencias retributivas entre los oficiales artesanos de Toledo y Madrid, década 1750 (en reales)

\begin{tabular}{|c|c|c|c|c|}
\hline & Gremios & Toledo & Madrid & Diferencia (\%) \\
\hline \multirow{3}{*}{ > en Toledo } & Albañiles & 7 & $4,5-6$ & $14,2-35,7$ \\
\hline & Tejedores seda & 7 & $4-6$ & $14,2-28,5$ \\
\hline & Jalmeros & 6 & 4 & 33 \\
\hline \multirow{3}{*}{ Igual } & Impresores, tintoreros seda & 7 & 7 & 0 \\
\hline & $\begin{array}{l}\text { Pasteleros, jalmeros, escultores, tallistas y ensambladores, } \\
\text { coleteros }\end{array}$ & 6 & 6 & 0 \\
\hline & Pasamaneros & 4,5 & 4,5 & 0 \\
\hline \multirow{19}{*}{$<$ en Toledo } & Cuchilleros & 4,5 & 5 & 10 \\
\hline & Plateros & 8 & $9,10,11,15$ & $12,2-46,6$ \\
\hline & Impresores, organeros, carreteros & 7 & 8 & 12,5 \\
\hline & Carpinteros & 7 & $8-10$ & $12,5-30$ \\
\hline & Libreros, cereros & 6 & 7 & 14,2 \\
\hline & Zurradores, guanteros, herreros obra negra & 5 & 6 & 16,6 \\
\hline & Zapateros obra prima & 5 & $6-7,5$ & $16,6-33,3$ \\
\hline & Cedaceros & 4 & 5 & 20 \\
\hline & Sombrereros & 7 & 9 & 22,2 \\
\hline & Guarnicioneros & 5 & $6,5-8,5$ & $23-41,1$ \\
\hline & Esparteros, boteros & 4,5 & 6 & 25 \\
\hline & Escultores, tallistas, ensambladores & 6 & $8,9,10$ & $25-33,3-40$ \\
\hline & Cabestreros, latoneros & 5 & 7 & 28,5 \\
\hline & Torneros, polvoristas, alfareros, guitarreros & 4 & 6 & 33,3 \\
\hline & Doradores & 6 & 9 & 33,3 \\
\hline & Zapateros de viejo & 3 & 5 & 40 \\
\hline & Herreros obra blanca, sastres & 6 & 10 & 40 \\
\hline & Albeitares & 3,5 & $6-10$ & $41,6-65$ \\
\hline & Caldereros & 4 & 8 & 50 \\
\hline
\end{tabular}

Fuente: respuestas del Catastro de Ensenada de Toledo y Matilla (1961).

\footnotetext{
3 Para las causas del siglo xvIII, AMT, Causa 5400 (caja 6382) y Causa 5428 (caja 6383). Para el resto hemos consultado en línea el inventario de causas facilitado por el propio archivo.
} 


\section{Tabla 8}

Diferencias retributivas entre aprendices artesanos de Toledo y Madrid, década 1750 (en reales)

\begin{tabular}{|c|c|c|c|c|}
\hline & Oficios & Toledo & Madrid & Diferencia (\%) \\
\hline \multirow{4}{*}{ > en Toledo } & Carpinteros, tejedores seda & 4 & 3 & 25 \\
\hline & Zapateros obra prima & 2,5 & 2 & 20 \\
\hline & Sastres & 3 & 2 & 33,3 \\
\hline & Albañiles & 4 & 3 & 25 \\
\hline \multirow{3}{*}{ Igual } & Tejedores seda & 4 & 4 & 0 \\
\hline & $\begin{array}{l}\text { Pasteleros, herreros obra blanca, cerrajeros, organeros, } \\
\text { prensadores lana, latoneros, batidores oro }\end{array}$ & 3 & 3 & 0 \\
\hline & Boteros & 2 & 2 & 0 \\
\hline \multirow{8}{*}{$<$ en Toledo } & $\begin{array}{l}\text { Cabestreros, guanteros, cordoneros, herreros obra } \\
\text { gruesa, herradores-albeitares, sombrereros, cereros }\end{array}$ & 2,5 & 3 & 16,6 \\
\hline & Carreteros, caldereros & 2 & 2,5 & 20 \\
\hline & Escultores, tallistas y ensambladores & 2 & $2,5-4$ & $20-50$ \\
\hline & Impresores & 3 & 4 & 25 \\
\hline & $\begin{array}{l}\text { Torneros, esparteros, jalmeros, zurradores, cedaceros, } \\
\text { hojalateros, doradores, guarnicioneros, pasamaneros, } \\
\text { plateros }\end{array}$ & 2 & 3 & 33,3 \\
\hline & Zapateros obra vieja & 1,5 & 4 & 62,5 \\
\hline & Cuchilleros & 1 & 3 & 66,6 \\
\hline & Alfareros & $1,25 \mathrm{mrs}$ & 6 & 70,8 \\
\hline
\end{tabular}

Fuente: respuestas del Catastro de Ensenada de Toledo y Matilla (1961).

tejedores de seda y jalmeros, mientras que los otros siete gremios estaban a la par que sus iguales madrileños. Pero en un total de 30 oficios la situación se desequilibraba en favor de los salarios satisfechos en Madrid, que iban desde el 10\% más de los cuchilleros hasta el $60 \%$ de los albeitares ${ }^{4}$. Si en Madrid los costes de afrontar el examen gremial se mantuvieron bajos en un buen número de oficios durante el xvIII, a un oficial toledano le podría salir a cuenta establecerse en Madrid para ganar destreza y acumular capital para obtener su título.

Las diferencias eran igualmente significativas entre los aprendices. En los 37 oficios en los que podemos comparar su retribución, los de Madrid ganaban más en 24 y los de Toledo solo salían beneficiados en 4 (carpinteros, zapateros de obra prima, sastres, albañiles). En general, los aprendices madrileños ganaban entre 0,5 y un real más que sus homólogos de la ciudad imperial, o lo que es igual, entre un 16,6 y un $25 \%$ más 5 . La cercanía a una ciudad en la que los maestros pagaban mejores salarios a la mano de obra auxiliar explica la retracción económica de Toledo.

No ha lugar a comparar aquí la evolución de los gremios de Madrid con los de Toledo. Los más de 9500 artesanos madrileños por 2044 de Toledo en 1750 hablan de una población

\footnotetext{
${ }^{4}$ En la Corte había gremios con una diversidad salarial que puede incluir varias retribuciones - por eso los jalmeros e impresores aparecen en varios rubros, lo mismo que otros gremios en la tabla del aprendizaje.

${ }^{5}$ Había casos de unas diferencias notables: los aprendices alfareros de Madrid recibían 6 reales por solo 1,25 los de Toledo, y los zapateros remendones de la Corte ganaban 4 reales por solo 1,5 los de Toledo.
}

menestral 4,6 veces mayor en la corte. Podría alegarse que Madrid pudo restar a Toledo muchos menestrales que decidieron acudir a la capital del imperio para continuar con su labor -ya eran maestros - o simplemente para conseguir la maestría. Pero los números son elocuentes: del total de 9331 cartas de examen localizadas en Madrid para el período 1700-1836, solo fueron concedidas 119 a naturales de la ciudad del Tajo, o el $1,27 \%$ de todas las emitidas en la Corte. Otra cosa era el incentivo que podían encontrar los toledanos de la provincia que vieron la posibilidad de realizar el examen en Madrid y establecerse en la Corte. Así lo hicieron 530 nuevos maestros en el mismo período, es decir, 4,5 veces más que los de la ciudad de Toledo. O lo que es igual, un 5,6\% de todos los nuevos maestros que engrosaron las filas de los gremios madrileños. Si consideramos que muchos de ellos nunca se hubieran instalado en Toledo debido, entre otras cosas, a un aumento del índice de precios de Toledo del 32,3\% durante el siglo xvIII (Llopis y García, 2011, p. 301), este drenaje de efectivos en favor de Madrid no supondría un problema importante desde el punto de vista demográfico para la ciudad del Alcázar, pero sí que lo haría en el orden económico, pues los derechos de examen engrosarían las arcas de las corporaciones madrileñas.

\section{Conclusiones}

¿Qué nos enseña la experiencia de Toledo y sus gremios en el siglo xviII? Toledo era una ciudad mediana que no sobrepasaba en el siglo xvII los 20000 habitantes. Ya era solo la sede de la mitra arzobispal, pues había dejado su papel político a 
favor de Madrid, y también había perdido parte de sus funciones industriales, en concreto su sedería y pañería de lana en favor de pequeñas villas cercanas.

Es aquí donde el tamaño de Toledo comienza a importar. Pese a su pérdida de peso con relación al entorno provincial, Toledo seguía siendo la principal ciudad de la meseta sur - tras Madrid-y ejercía un influjo importante mediante la concesión de las cartas de examen que certificaban la destreza de los nuevos maestros de estas localidades. A diferencia de las pequeñas ciudades alemanas analizadas por Ogilvie, en Castilla estas no pudieron disfrutar de autonomía y siguieron dependiendo de las ciudades cabecera en aspectos como la concesión de los títulos, lo que tuvo consecuencias en la configuración de los mercados de trabajo cualificado.

Además, el análisis de los gremios de Toledo que aquí hemos realizado difiere de lo sostenido por los partidarios del monopolio gremial. En primer lugar, porque lejos de controlar a su concejo, los gremios toledanos estuvieron a merced de la política municipal. Y en segundo, porque los gremios de Toledo mostraron a lo largo del siglo xvIII unos rasgos estructurales distintos a los defendidos por los partidarios del cierre gremial. De hecho, en su decadencia sorprenden algunas de las respuestas gremiales a la crisis. Primero, en el ámbito reproductivo: salvo un puñado de gremios, no hubo una endotecnia acusada. Segundo, en cuanto a la edad de acceso: a excepción de los gremios de la construcción, la edad de entrada a la maestría rondó los treinta años, lo que significa que en el siglo xviII no se alargó en exceso la posibilidad de abrir un taller en la ciudad. Tercero, en la procedencia geográfica: buena parte de los nuevos maestros eran de Toledo, pero otros eran vecinos de la provincia que utilizaban la ciudad para lograr el título y ejercer donde estaban avecindados.

El problema era que Toledo tenía un potente competidor en Madrid. En un principio, la cercanía de la corte, donde los salarios artesanales eran más altos y las tasas de examen eran bajas, pudo incentivar la migración a la corte de los aspirantes a maestros. Pero no parece que Madrid drenara a su favor un flujo significativo de nuevos maestros de procedencia toledana, mientras que sí hubo un flujo de los de su provincia que pudieron beneficiarse de un índice de precios que no crecía como en Toledo.

\section{Agradecimientos}

Este trabajo se ha realizado gracias al proyecto de investigación PGC2018-094150-B-C22, «Privilegio, trabajo y conflictividad: la sociedad moderna de Madrid y su entorno entre el cambio y las resistencias». Agradezco a los evaluadores su contribución a la mejora del borrador inicial. También quiero reconocer la ayuda de Eduardo Velasco Merino y Francisco Sanz de la Higuera a la hora de recopilar los datos de varias ciudades de Castilla. Y la amabilidad en el trato personal del Archivo Municipal de Toledo.

\section{Bibliografía}

Aranda, F.J. (1992). Poder municipal y cabildo de jurados en Toledo en la Edad Moderna (siglos XV-XVIII). Toledo: Concejalía de Cultura.

Belfanti, C. M. (2004). «Guilds, patents and the circulation of technical knowledge: Nothern Italy during the Early Modern Age», Technology and Culture, 45(3), pp. 569-589.
Benaul, J. M. (1992). «Los orígenes de la empresa textil lanera en Sabadell y Terrassa en el siglo xvIII", Revista de Historia Industrial, 1, 39-62.

Bernal, A., Collantes de Terán, A. y García-Baquero, A. (1978). «Sevilla, de los gremios a la industrialización", Estudios de Historia Social, 5-6, 7-307.

Díez, F. (1990). Viles y mecánicos. Trabajo y sociedad en la Valencia preindustrial. Valencia: Alfons El Magnánim.

Epstein, S. R. y Prak, M. (eds.) (2008). Guilds, Innovation, and the European Economy, 1400-1800. Cambridge: Cambridge University Press.

Franch, R., Muñoz, D. y Rosado, L. (2016). "La reproducción de los maestros y la transformación de las condiciones sociales de los miembros del Colegio del Arte Mayor de la seda de Valencia en el siglo xVIII), Revista de Historia Industrial, 65, 15-49.

García Ruipérez, M. (1986). La Real Compañía de Comercio y Fábricas de Toledo. Toledo: Caja de Ahorros de Toledo.

García Sanz, Á. (1996). «Verlagssystem y concentración productiva en la industria pañera de Segovia durante el siglo xviii», Revista de Historia Industrial, 10, 11-36.

González Agudo, D. (2015). Población, precios y renta de la tierra en Toledo, siglos xvi-xvii [tesis doctoral]. Madrid: Universidad Complutense de Madrid.

Lis, C. y Soly, H. (2008). «Subcontracting in guild-based export trades, Thirteenth-Eigtheenth Centuries», en Epstein, S. y Prak, M. (eds.). Guilds, Innovation and the European Economy, 1400-1800. Cambridge: Cambridge University Press, pp. 81-113.

Llopis, E. y García, H. (2011). «Precios y salarios en Madrid, 1680-1850», Investigaciones de Historia Económica, 7, pp. 295-309.

Llopis, E. y Pérez Moreda, V. (2003). «Evolución demográfica de la zona centro de España a través de los índices de bautismos, 1580-1850», en Estudios de Historia de pensamiento económico. Homenaje al Profesor Francisco Bustelo García del Real, Madrid: Universidad Complutense de Madrid, pp. 113-146.

Lucassen, J., De Moor, T. y Van Zanden, J. L. (eds.) (2008). «The Return of the Guild», International Review of Social History, Supplement 16.

Martín, A. (1858). Ordenanzas para el buen régimen y gobierno de la muy noble, muy leal e imperial ciudad de Toledo. Toledo: Imprenta de José Cea.

Matilla, A. (1961). «El primer Catastro de la Villa de Madrid», Revista de Archivos, Bibliotecas y Museos, 69, 463-530.

Mocarelli, L. (2008). "Guilds reappraised: Italy in the Early Modern Period" in Lucassen, J., De Moor, T., Van Zanden, J. L. (eds.). The Return of the Guild. International Review of Social History, Supplement 16, Cambridge, pp. 159-178

Montemayor, J. (1996). Tolède entre fortune et déclin: 1530-1640. Limoges: Presses Universitaires de Limoges.

Munck, B. (2007). Technologies of Learnings: Apprenticeship in Antwerp Guilds from the $15^{\text {th }}$ Century to the End of the Ancien Regime. Turnhout: Brepols.

Muñoz, D. y Franch, R. (2020). «El artesanado sedero y las fluctuaciones del mercado laboral en la Valencia preindustrial (1479-1836)», Investigaciones de Historia Económica, avance on line.

Nieto, J. A. (1999). La protoindustrialización en Castilla, 1350-1850 [tesis doctoral]. Madrid: UAM.

Nieto, J. A. (2000). «Nebulosas industriales y capital mercantil urbano. Castilla la Nueva y Madrid, 1750-1850», Sociología del Trabajo, 39, 85-109.

Nieto, J. A. (2006). Artesanos y mercaderes: una historia social y económica de Madrid, 1450-1850. Madrid: Fundamentos.

Nieto, J. A. (2012). «Redes comerciales madrileñas e industria textil castellano-manchega en la primera mitad del siglo xviIIn, en Hernando J., López, J. M. y Nieto, J. (eds.). La historia como arma de reflexión. Estudios en homenaje al profesor Santos Madrazo. Madrid: UAM Ediciones, pp. 215-228.

Nieto, J. A. (2013). «El acceso al trabajo corporativo en el Madrid del siglo xviII: una propuesta de análisis de las cartas de examen gremial», Investigaciones de Historia Económica, 9, 97-107.

Nieto, J. A. y Zofío, J. C. (2015). «Los gremios de Madrid durante la Edad Moderna: una revisión", Áreas, 34, 47-61.

Nieto, J. A. y Zofío, J. C. (2016). "The Return of the Guilds. A View from Early Modern Madrid», Journal of Social History, 50, 247-272. 
Nieto, J. A. y Velasco, E. (2018). «Mercados de trabajo artesano en Castilla al final del Antiguo Régimen", en Amelang, J. et al. (coords.). Palacios, plazas, patíbulos: la sociedad española moderna entre el cambio y las resistencias. Valencia: Tirant Lo Blanc, pp. 69-82.

Nombela, J. M. (2003). Auge y decadencia en la España de los Austrias. La manufactura textil de Toledo en el siglo xvI. Toledo: Ayuntamiento de Toledo.

Ogilvie, S. (2019). The European Guilds: An Economic Analysis. Princenton; Oxford: Princeton University Press.

Pérez, L. (2008). "Inventing in a world of guilds: silk fabrics in Eighteenth century Lyon", en Epstein, S. R. y Prak, M. (eds.). Guilds, innovation and the European economy, 1400-1800. Cambridge: Cambridge University Press, pp. 232-263.

Prak, M. (2008). «Painters, Guilds and the Art Market during the Dutch Golden Age», en Epstein, S. R. y Prak, M. (eds.), Guilds, innovation and the European economy, 1400-1800. Cambridge: Cambridge University Press, pp. 143-171.

Prak, M. et al. (2019). "Access to the trade. Monopoly and Mobility in European Craft Guilds in the Seventeenth and Eighteenth Centuries", Journal of Social History. 52, 1-32.

Prak, M. y Wallis, P. (eds.) (2020). Apprenticeship in Early Modern Europe. Cambridge: Cambridge University Press.

Reith, R. (2008). "Circulation of skilled labour in Late Medieval and Early Modern Central Europe», en Epstein, S. R. y Prak, M. (eds.). Guilds, innovation and the European Economy, 1400-1800, Cambridge: Cambridge University Press, pp. 114-142.

Sáez, E. (1944). «Ordenanzas de los gremios de Toledo», Revista de Trabajo, 10, 1233-1241.

Sáez, E. (1945a). "Ordenanzas de los gremios de Toledo», Revista de Trabajo, 1, 39-49.
Sáez, E. (1945b). «Ordenanzas de los gremios de Toledo», Revista de Trabajo, 7-8, 689-700.

Sáez, E. (1946). "Ordenanzas de los gremios de Toledo», Revista de Trabajo, 5, 495-505.

Sáez, E. (1947a). "Ordenanzas de los gremios de Toledo», Revista de Trabajo, 1, 24-32.

Sáez, E. (1947b). "Ordenanzas de los gremios de Toledo», Revista de Trabajo, 5, 518-522.

Santos, Á. (2010). La industria textil sedera de Toledo. Cuenca: Universidad de Castilla La Mancha.

Santos, Á. (1998). «Vicente Díaz Benito: El mercader-fabricante sedero más poderoso de Toledo en el siglo xviii», Anales Toledanos, 36, $115-131$.

Sanz, F. (2019). «El devenir de la apertura de tiendas y la consecución del magisterio artesano como "proxy-data" económico urbano en el Burgos del setecientos", Trocadero. 31, 102-126.

Shephard, E. J. (1996). «Movilidad social y geográfica del artesanado en el siglo xviII: estudio de la admisión a los gremios de Dijon, 170090», en López, V. y Nieto, J. A. (eds.). El trabajo en la encrucijada: los artesanos urbanos en la Europa de la edad moderna. Madrid: Los Libros de la Catarata, pp. 37-69.

Solà, À. y Yamamichi, Y. (2015). «Del aprendizaje a la maestría. El caso del gremio de velers de Barcelona, 1770-1834», Áreas, 34, 77-91.

Torras, J. (2019). La industria antes de la fábrica. Salamanca: Ediciones Universidad de Salamanca.

Torró, Ll. (2004). «Procedimientos técnicos y conflictividad gremial: el ancho de los peines de los telares alcoyanos (1590-1797)», Revista de Historia Industrial, 25, 165-184.

Villas, S. (1982). Los gremios malagueños, 1700-1746. Málaga: Universidad de Málaga. 